\title{
Structure and biological functions of fungal cerebrosides
}

\author{
ELIANA BARRETO-BERGTER, MARCIA R. PINTO and MARCIO L. RODRIGUES
}

Instituto de Microbiologia Professor Paulo de Góes, Departamento de Microbiologia Geral Universidade Federal do Rio de Janeiro, Cidade Universitária, CCS, Bl. I, Ilha do Fundão 21941-590 Rio de Janeiro, RJ, Brasil

Manuscript received on October 20, 2003; accepted for publication on October 22, 2003; presented by $\mathrm{L}$. R. TRAVAsSOS

\begin{abstract}
Ceramide monohexosides (CMHs, cerebrosides) are glycosphingolipids composed of a hydrophobic ceramide linked to one sugar unit. In fungal cells, CMHs are very conserved molecules consisting of a ceramide moiety containing 9-methyl-4,8-sphingadienine in amidic linkage to 2-hydroxyoctadecanoic or 2-hydroxyhexadecanoic acids, and a carbohydrate portion consisting of one residue of glucose or galactose. 9-Methyl 4,8-sphingadienine-containing ceramides are usually glycosylated to form fungal cerebrosides, but the recent description of a ceramide dihexoside (CDH) presenting phytosphingosine in Magnaporthe grisea suggests the existence of alternative pathways of ceramide glycosylation in fungal cells. Along with their unique structural characteristics, fungal CMHs have a peculiar subcellular distribution and striking biological properties. In Pseudallescheria boydii, Candida albicans, Cryptococcus neoformans, Aspergillus nidulans, A. fumigatus, and Schizophyllum commune, CMHs are apparently involved in morphological transitions and fungal growth. The elucidation of structural and functional aspects of fungal cerebrosides may therefore contribute to the design of new antifungal agents inhibiting growth and differentiation of pathogenic species.
\end{abstract}

Key words: glucosylceramide, cerebrosides, glycosphingolipids, fungal pathogens, antifungal therapy.

\section{INTRODUCTION}

The frequency of fatal mycoses associated with immunosuppression has increased in the last two decades (Dromer and Dupont 1996). Despite the clinical relevance of fungal infections, however, the current antifungal therapy is ineffective in several cases. For over four decades, the principal target of antifungal therapy has been ergosterol in the fungal cell membrane. Although this has proven to be a successful and relatively selective antifungal target, reports of resistance and intolerance to currently available antifungal agents are increasing. In this context, the search for novel antifungal agents has

Correspondence to: Eliana Barreto-Bergter

E-mail: eliana.bergter@micro.ufrj.br been greatly stimulated.

Glycosphingolipids (GSLs) consist of a ceramide ( $N$-acylsphingosine) moiety linked to a glycan chain of variable length and structure. These molecules have been implicated in many fundamental cellular processes including growth, differentiation, and morphogenesis. GSLs may also modulate cell signaling by controlling the assembly and specific activities of plasma membrane proteins (Hakomori 1993, Kasahara and Sanai 2000). Several natural product inhibitors of sphingolipid biosynthesis have been discovered in recent years (Georgopapadakou 2000), and some of them exhibit a potent and selective antifungal activity.

The roles of fungal monohexosylceramides 
(CMHs, cerebrosides) elucidated in the last three years suggests that a new target for antifungal therapy may emerge (Rodrigues et al. 2000, Pinto et al. 2002, Levery et al. 2002). Cerebrosides are neutral glycosphingolipids that contain a monosaccharide, normally glucose or galactose, in 1-ortho-betaglycosidic linkage with the primary alcohol of an $N$ acyl sphingoid (ceramide). In plants the monosaccharide is normally glucose and the sphingoid usually phytosphingosine. In animals, the monosaccharide is usually galactose, though this may vary with the tissue and the sphingoid is usually sphingosine or dihydrosphingosine. Since cerebrosides contain one sugar unit, they are also called ceramide monohexosides (CMHs), differing from gangliosides in that the latter contain at least one sialic acid residue. CMHs also differ from globosides in that these glycolipids contain multiple sugar moieties, whereas cerebrosides only contain one.

\section{STRUCTURAL ASPECTS OF FUNGAL CEREBROSIDES}

CMHs have been widely detected in fungal cells (reviewed by Warnecke and Heinz 2003). The current literature indicates that cerebrosides seem to be present in almost all fungal species studied so far, with Saccharomyces cerevisiae representing a wellknown exception. Fungal cerebrosides are much conserved structures, in which modifications include different sites of unsaturation as well as the varying length of fatty acid residues in the ceramide moiety (Table I). Fungal CMHs contain a ceramide moiety with 9-methyl-4, 8-sphingadienine in amidic linkage to 2-hydroxyoctadecanoic or 2-hydroxyhexadecanoic acids, and a carbohydrate portion consisting of one residue of glucose or galactose. Exceptionally, cerebrosides from S. kluyveri have an extremely rare trihydroxy sphingoid base as a unique feature (Takakuwa et al. 2002).

The long chain base 9-methyl-4,8-sphingadiene was first described in monohexosylceramides from Aspergillus oryzae (Fujino and Ohnishi 1977) and was subsequently isolated from Schizophyllum commune (Kawai and Ikeda 1982), from the plant
TABLE I

Fungal CMHs: ceramide* and carbohydrate moieties.

\begin{tabular}{l|c|l}
\hline Fungal specie & Major fatty acid & Sugar \\
\hline $\begin{array}{l}\text { A. fumigatus } \\
\text { A. versicolor }\end{array}$ & $\mathrm{C}_{18: 1(\mathrm{OH})}$ & Glucose/ \\
A. flavus & & Galactose \\
\hline P. boydii & $\mathrm{C}_{16: 0(\mathrm{OH})}$ & Glucose \\
& $\mathrm{C}_{18: 0(\mathrm{OH})}$ & \\
\hline Fusarium $\mathrm{sp}$ & $\mathrm{C}_{16: 0(\mathrm{OH})}$ & Glucose \\
F. oxysporum & $\mathrm{C}_{18: 0(\mathrm{OH})}$ & \\
F. solani & $\mathrm{C}_{18: 1(\mathrm{OH})}$ & \\
\hline P. brasiliensis & $\mathrm{C}_{18: 0(\mathrm{OH})}$ & Glucose \\
& $\mathrm{C}_{18: 1(\mathrm{OH})}$ & \\
\hline H. capsulatum & $\mathrm{C}_{18: 0(\mathrm{OH})}$ & Glucose \\
& $\mathrm{C}_{18: 1(\mathrm{OH})}$ & \\
\hline C. neoformans & $\mathrm{C}_{18: 0(\mathrm{OH})}$ & Glucose \\
\hline C. albicans & $\mathrm{C}_{18: 0(\mathrm{OH})}$ & Glucose \\
\hline M. grisea & $\mathrm{C}_{18: 1(\mathrm{OH})}$ & Glucose \\
\hline S. schenckii & $\mathrm{C}_{18: 0(\mathrm{OH})}$ & Glucose/ \\
& $\mathrm{C}_{18: 1(\mathrm{OH})}$ & Galactose \\
\hline
\end{tabular}

*9-Methyl-4,8-sphingadienine is the long chain base composing the ceramide unit of all the molecules described in this table.

pathogen Fusicoccum amygdali (Ballio et al. 1979), and the edible fungi Clitocybe geotrope and C. nebularis (Fodegal et al. 1986). CMHs were further characterized in lipid extracts from the fungal species Aspergillus fumigatus (Toledo et al. 1999, VillasBoas et al. 1994a), A. niger (Levery et al. 2000), A. versicolor (Villas-Boas et al. 1994a), Acremonium chrysogenum (Sakaki et al. 2001), Amanita muscaria (Weiss and Stiller 1972), A. rubescens (Weiss and Stiller 1972), Candida albicans (Matsubara et al. 1987), C. deformans (Mineki et al. 1994), C. utilis (Wagner and Zofcsik 1966a, Wagner and Zofcsik 1966b), Colletotrichum gloeosporioides (Da Silva et al. unpublished), Cryptococcus neoformans (Rodrigues et al. 2000), Fonsecaea pedrosoi (Nimrichter et al. unpublished), Fusarium sp (Duarte et al. 1998), Ganoderma lucidum (Mizushina et al. 1998), Hansenula anomala ( $\mathrm{Ng}$ and Laneelle 1977), Histoplasma capsulatum (To- 
ledo et al. 2001a), Hypsizigus marmoreus (Sawabe et al. 1994), Kluyveromyces waltii (Takakuwa et al. 2002), K. thermotolerans (Takakuwa et al. 2002), K. lactis (Takakuwa et al. 2002), Lentinus edodes (Kawai 1989), Magnaporthe grisea (Umemura et al. 2000, Koga et al. 1998), Metridium senile (Karlsson et al. 1979), Paracoccidioides brasiliensis (Takahashi et al. 1996), Pichia pastoris (Sakaki et al. 2001), Polyporus ellisii (Gao et al. 2001), Pseudallesheria boydii (Pinto et al. 2002), Rhynchosporium secalis (Sakaki et al. 2001), Saccharomyces klyuyveri (Takakuwa et al. 2002), Sordaria macrospora (Sakaki et al. 2001), Sporothrix schenckii (Toledo et al. 2000), Termitomyces albuminosus (Qi et al. 2001), Zygosaccharomyces cidri (Takakuwa et al. 2002), and Z. fermentati (Takakuwa et al. 2002).

\section{ANALYSIS OF CMHs}

The methodology described here follows the steps of purification routinely used in our laboratory for CMH extraction and purification (Villas-Boas et al. 1994a, Duarte et al. 1998, Pinto et al. 2002), but different methods are available in the current literature for isolation and purification of CMHs (Takakuwa et al. 2002, Fujino and Ohnishi 1977, Kawai and Ikeda 1982, Ballio et al. 1979, Fodegal et al. 1986, Toledo et al. 1999, Levery et al. 2000, Matsubara et al. 1987, Toledo et al. 2001a, Levery et al. 2002, Takakuwa et al. 2002, Umemura et al. 2000, Koga et al. 1998, Takahashi et al. 1996, Sakaki et al. 2001, Toledo et al. 2000). Using mixtures of chloroform and methanol followed by chromatographic steps of purification, cerebrosides can be satisfactorily purified for further physicochemical analysis.

Fungal cells are first extracted with chloroform/ methanol (2:1 and 1:2 v/v). These extracts are usually combined and dried, yielding a crude lipid mixture. The crude extract is subsequently partitioned according to Folch et al. (1957), in which the lower phase containing neutral GSLs is taken for further analysis.

CMHs, present at the Folch's lower layer, are purified by chromatographic methods, initially on silica columns. Glycolipids are recovered by elution with chloroform, acetone and methanol. The acetone and methanol fractions, containing CMHs, are further purified on another silica gel column, which is sequentially eluted with chloroform/methanol with increasing concentrations of methanol (95:5, 9:1, 8:2 and $1: 1 \mathrm{vol} / \mathrm{vol}$ ) and finally with $100 \%$ methanol. The presence of CMHs is monitored by high performance thin-layer chromatography (HPTLC), on silica plates developed with chloroform/methanol/ water $(65: 25: 4 \mathrm{vol} / \mathrm{vol})$. The separated glycolipids are visualized with iodine vapor and by spraying with orcinol/sulfuric acid. Fractions containing CMHs, usually those eluted with chloroform/methanol (9:1 and 8:2 vol/vol), can be further purified by chromatography on Iatrobeads RS 2060, using the same elution system, normally yielding a purified CMH fraction. A typical example of the purification of cerebrosides and related molecules is given in Figure 1.

Purified CMH fractions can then be submitted to structural determinations. The sugar composition is achieved by hydrolysis of glycosphingolipids with $3 \mathrm{M}$ trifluoroacetic acid at $100^{\circ} \mathrm{C}$ for $3 \mathrm{~h}$, with preliminary analysis of the resulting monosaccharides by thin layer chromatography. Sugar quantification is determined by gas chromatography (GC), after chemical conversion of the monosaccharides to the alditol-acetate derivatives (Sawardeker et al. 1965). Fatty acid components are prepared as their methyl ester derivatives, by acid methanolysis using $1 \mathrm{~mL}$ of toluene/methanol ( $1: 1 \mathrm{vol} / \mathrm{vol})$ containing $2.5 \%$ concentrated sulfuric acid (overnight at $70^{\circ} \mathrm{C}$ ). Samples are diluted in deionized water and extracted twice with hexane/chloroform (4:1 vol/vol), followed by pooling extracts and trimethylsilylation by treatment with $100 \mu \mathrm{L}$ of bis-(trimethylsilyl) trifluoracetamide/pyridine. Samples are then analyzed by the combination of gas chromatography and massspectrometry (GC-MS).

The particular use of mass spectrometry is of fundamental relevance in the structural determination of CMHs from different species, including analytical variations as fast atom bombardment mass 


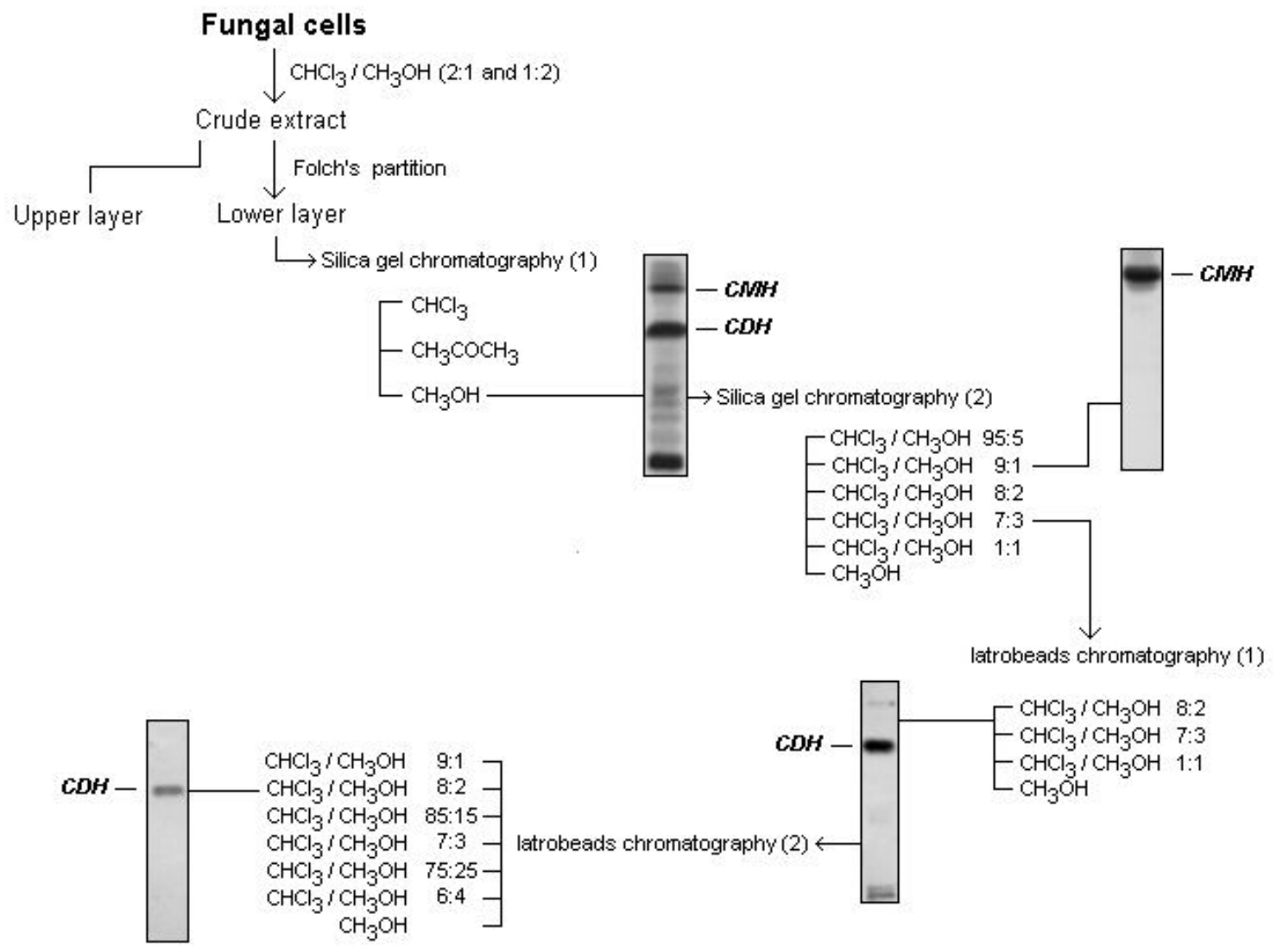

Fig. 1 - Overview of the strategy used for purification of CMHs and CDHs from fungal cells (modified from Maciel et al. 2002). Purified or partially purified extracts are usually resolved by HPTLC and visualized by reaction with orcinol- $\mathrm{H}_{2} \mathrm{SO}_{4}$.

spectrometry (FAB/MS), electrospray ionization (ESI-MS) and low energy collision-induced dissociation mass spectrometry (ESI-MS/CID-MS). Nuclear magnetic resonance $\left({ }^{1} \mathrm{H}\right.$ and $\left.{ }^{13} \mathrm{C}\right)$ has been also successfully used in $\mathrm{CMH}$ structural analyses. The combination of these techniques is usually satisfactory for a complete structural elucidation of $\mathrm{CMHs}$, and a vast and detailed literature is available on this subject (Takakuwa et al. 2002, Fujino and Ohnishi 1977, Kawai and Ikeda 1982, Ballio et al. 1979, Fodegal et al. 1986, Toledo et al. 1999, Levery et al. 2000, Villas-Boas et al. 1994a, Matsubara et al. 1987, Da Silva et al. unpublished, Rodrigues et al. 2000, Nimrichter et al. unpublished, Duarte et al. 1998, Toledo et al. 2001a, Levery et al. 2002, Takakuwa et al. 2002, Umemura et al. 2000, Koga et al. 1998, Takahashi et al. 1996, Sakaki et al.
2001, Pinto et al. 2002, Toledo et al. 2000).

\section{BIOSYNTHESIS OF FUNGAL CEREBROSIDES}

Synthesis and expression of sphingolipids seems to be essential for normal processes in microbial and animal cells. Fungal cells possess some exclusive pathways of sphingolipid biosynthesis, some of which are crucial to cell viability. For that reason, synthesis of sphingolipids is emerging as an attractive target for the action of antifungal drugs (Georgopapadakou 2000). Several inhibitors of sphingolipid synthesis in fungi, all natural products and most of them non-toxic to mammalian cells, have been in fact reported in the last decade. This observation agrees with the fact that, between fungal and mammalian cells, glycosphingolipids differ in structure and biosynthesis. The understanding of 
GSL biosynthesis is, therefore, fundamental for the development of antifungal drugs and for the complete knowledge of lipid function in fungal cells. In addition, studies on the functions and biosynthesis of GSLs are stimulated because of their antigenicity and involvement with fungal pathogenesis (Rodrigues et al. 2000, Pinto et al. 2002, Levery et al. 1998, 2002).

Long-chain bases (LCBs) are the characteristic structural units of GSLs. They are long-chain aliphatic amines, containing two or three hydroxyl groups, therefore consisting of 2-amino-1,3-dihydroxy linear alkanes. LCBs are used in the synthesis of ceramides, the building blocks of sphingolipids. Ceramides consist of an LCB linked to a fatty acid via an amide bond. The formation of ceramides is a key step in the biosynthesis of all the complex sphingolipids, in which the terminal primary hydroxyl group is, for instance, linked to carbohydrate or phosphate units.

Most of the knowledge on sphingolipid biosynthesis comes from studies using the model yeast S. cerevisiae. Several genes involved in the metabolism of sphingolipids have been identified in this organism (reviewed in Dickson and Lester 2002, Obeid et al. 2002) and, in this context, $S$. cerevisiae represents an excellent model for studies on the biosynthesis and expression of fungal GSLs. However, it is worthwhile to remember that there are clear differences between the expression of glycosphingolipids in S. cerevisiae and other fungal species; for instance, monohexosylceramides, which are the major subject of this review, are commonly detected in pathogenic and non-pathogenic fungi, but not in S. cerevisiae.

The process resulting in the synthesis of ceramide begins with the condensation of palmitoyl$\mathrm{CoA}$ and serine in the endoplasmic reticulum. This reaction, which occurs in both animal and fungal cells, is catalyzed by the enzyme serine palmitoyltransferase (SPT), resulting in the generation of the intermediary compound 3-ketodihydrosphingosine (3-ketosphinganine). In S. cerevisiae, three genes are required for optimal SPT activity: the homol- ogous genes $L C B 1$ and $L C B 2$, which are involved in the yeast response for heat stress, and TSC3, a member of the family of temperature-sensitive suppressors of calcium sensitivity (TSC) (Dickson and Lester 2002, Obeid et al. 2002). The condensation of serine and palmitoyl-CoA is followed by the reduction of 3-ketosphinganine to the LCB dihydrosphingosine (DHS, sphinganine). This step also occurs in the endoplasmic reticulum and involves the action of 3-ketosphinganine reductase, whose deletion renders $S$. cerevisiae cells unable to grow in the absence of exogenous LCBs. The 3ketosphinganine reductase, encoded by the TSC10 gene, also belongs to the TSC family (Dickson and Lester 2002, Obeid et al. 2002).

The generation of sphinganine gives rise to the first branching point in fungal sphingolipid synthesis. This LCB is hydroxylated, to generate phytosphingosine and afterwards inositolphosphorylceramide, or used in the synthesis of monohexosylceramides. These distinct pathways of the sphingolipid metabolism will be discussed below in more detail and are summarized in Figure 2.

\section{Synthesis and Glycosylation of Ceramides in Fungal Cells}

In mammalian cells, sphinganine is acylated to generate dihydroceramide. The latter is then reduced, resulting in the synthesis of ceramide. This observation diverges from the corresponding pathways observed in yeast cells, in which sphinganine can be hydroxylated to form phytosphingosine, which is then converted to phytoceramide by transfer of acyl groups. Alternatively, sphinganine can be first acylated, generating dihydroceramide, and then hydroxylated, finally forming phytoceramide. In $S$. cerevisiae, the enzyme encoded by the gene SUR2/ $S Y R 2$ catalyzes the hydroxylation of either dihydrosphingosine or dihydroceramide (Dickson and Lester 2002, Obeid et al. 2002). Acylation of LCB and consequent synthesis of ceramide also differs in mammalian and fungal cells, since the latter appear to exclusively transfer $\alpha$-hydroxylated very longchain fatty acids (VLCFAs) to phytosphingosine. 


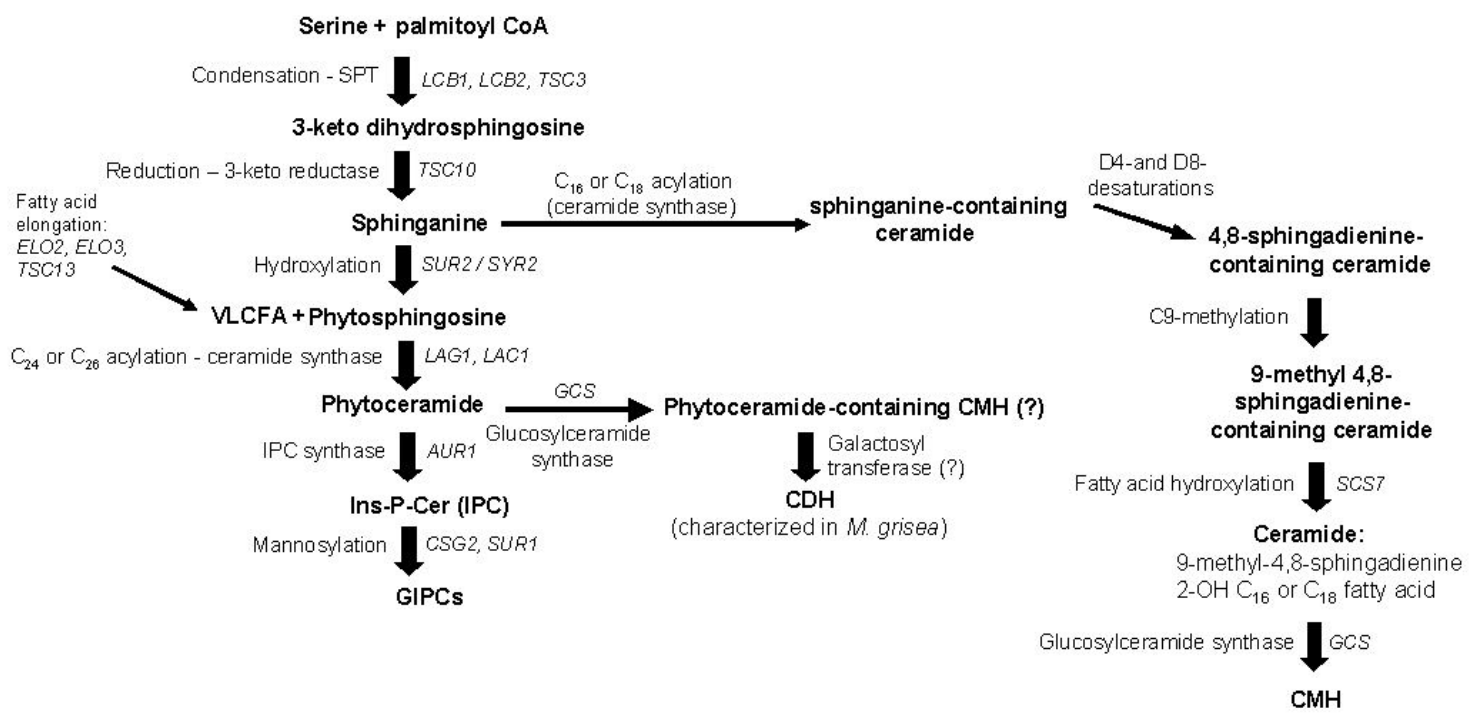

Fig. 2 - Overview of the biosynthetic pathways for cerebroside biosynthesis in fungi.

VLCFAs are formed through the action of the enzymes encoded by $E L O 2$ and $E L O 3$, responsible for the sequential elongation of smaller fatty acids to 24 carbons (Elo2p) and conversion of $24 \mathrm{C}$ to $26 \mathrm{C}$ fatty acids (Elo3p) (Dickson and Lester 2002, Obeid et al. 2002). The enzyme responsible for transferring these fatty acids to LCB is called ceramide synthase, encoded by $L A G 1$ and its homologue $L A C 1$, and its action is inhibited by the fungal toxin fumonisin (Dickson and Lester 2002, Obeid et al. 2002).

Steps subsequent to phytoceramide formation are unique to fungi and involve the sequential addition of phosphorylated inositol to form inositolphosphorylceramide (IPC), mannose-IPC (MIPC) and, specially in S. cerevisiae, mannose-inositolphosphoryl-IPC $\left(\mathrm{M}(\mathrm{IP})_{2} \mathrm{C}\right)$. Such compounds are frequently glycosylated to produce most complex glycosphingolipids, generating the fungal glycoinositol phosphorylceramides (GIPCs).

To form IPC, the C1-hydroxyl group of phytoceramide is linked to phosphoinositol by a phosphodiester bond. This reaction is catalyzed by IPC synthase, (Ipc1p), encoded by the AURl gene (Heidler and Radding 1995). Because Ipclp activity is both vital and unique in fungi, it has emerged as an attractive target for antifungal drugs (Georgopa- padakou 2000). The antifungal peptide aureobasidin A (AbA), produced by Aureobasidium pullulans, has a strong activity against many pathogens and its molecular target was identified in $S$. cerevisiae as the essential gene AUR1. This gene is required for the expression of Ipc1p and formation of IPC in yeast. Therefore the AURI gene is also called IPC1. Currently, two additional antifungal agents (khafrefungin and rustmicin) targeting Ipc1p are known (Dickson and Lester 2002, Obeid et al. 2002).

IPCl was the first gene of the sphingolipid pathway to be implicated in fungal pathogenesis. IPCl modulated some virulence factors of $C$. neoformans, such as melanin pigmentation. Overexpression of the gene increased melanin production, whereas down-regulation decreased melanin pigmentation (Luberto et al. 2001). One major factor favoring C. neoformans infection is its ability to grow inside macrophages and, therefore, in acidic conditions, as in phagolysosomes. Down-regulation of IPCl generated a strain no longer pathogenic in a rabbit model of cryptococcal meningitis. In addition, a decreased Ipc1p level impaired the $C$. neoformans growth in a macrophage cell line and in an acidic environment. 
Concomitant to IPC formation, Ipc $1 \mathrm{p}$ also produces diacylglycerol (DAG) and consumes phytoceramide. The importance of Ipc1p therefore may be due not only to the formation of IPC itself, one of the most abundant sphingolipids in the membrane, but also to the regulation of phytoceramide, implicated in growth arrest and yeast stress responses (Jenkins et al. 1997, Chung et al. 2001), and DAG, a wellestablished mitogen and activator of protein kinase C (PKC).

In $S$. cerevisiae, IPC is mannosylated to yield mannose-inositol-phosphoceramide (MIPC), a reaction that requires the SURI and CSG2 genes (Dickson and Lester 2002). Similar reactions should occur in several other fungal species, which appear to use MIPC as the precursor for more complex GSLs. The human pathogen Sporothrix schenckii seems to represent an exception, since a novel GSL containing a glucosamine-inositol - phosphoceramide motif has been described, in addition to GSLs containing the conventional MIPC domain (Dickson and Lester 2002). In S. cerevisiae, the terminal step in sphingolipid synthesis involves the addition of inositol phosphate to MIPC. This reaction, which requires the product of the IPT1 gene, results in the formation of M(IP)2C (Dickson and Lester 2002, Obeid et al. 2002).

Several fungal species further carry out sphingolipid biosynthesis by adding several sugar residues to IPC (as in the case of $S$. schenckii) or MIPC (as in the case of the pathogens $C$. albicans, $C$. neoformans, S. schenckii, H. capsulatum, P. brasiliensis, A. fumigatus, and the high mushrooms Amanita virosa, Calvatia exipuliformis, Cantharellus cibarius, Leccinum scabrum, Lentinus edodes, and Pleurotus ostreatus. The resulting structures are the acidic GSLs glycosylinositol phosphorylceramides, which represent a major class of fungal lipids characterized by the presence of a myoinositol-1-phosphate spacer between glycan and ceramide. As already mentioned, this class of molecules is synthesized by fungi, plants, and certain parasitic organisms, but not by mammalian cells or tissues. The detailed structural characterization of GIPCs from different fungal species revealed a relatively great diversity, which requires the use of several still uncharacterized glycosyltransferases.

All sphingolipids in $S$. cerevisiae are classified as IPCs (Dickson and Lester 2002). Several other fungal species, however, add one or more sugar residues to the $\mathrm{C}-1$ of ceramide to form a second class of sphingolipids referred to as glycosylceramides. CMHs, which are the most common examples of such neutral GSLs, were characterized in detailed in several fungal species (Table I), all of them showing a ceramide moiety containing 9-methyl-4,8-sphingadienine in amidic linkage to $\mathrm{C} 18$ or $\mathrm{C} 16 \alpha$-hydroxy fatty acids and a carbohydrate unit. These molecules are formed through the action of UDP-glycosyl ceramide glycosyltransferases (glycosylceramide synthases, GCS), which may also act in the synthesis of ceramide dihexosides (CDHs) (Maciel et al. 2002). Molecular studies using GCS from different organisms (Takakuwa et al. 2002, Leipelt et al. 2001) provided new insights into the biosynthesis of sphingolipids, as described below.

Ceramide backbones with $\mathrm{C} 16$ or $\mathrm{C} 18$ fatty acids linked to the 4,8-diene-9-methyl-sphingobase are exclusive precursors for $\mathrm{CMH}$ synthesis, whereas ceramide backbones containing VLCFAs and phytosphingosine are preferentially used as substrates for the synthesis of inositol-containing sphingolipids. However, through a systematic analysis of the glycosyltransferase gene family with members from animals, plants, fungi, and bacteria, Leipelt et al. (2001) suggested the occurrence of previously unknown steps of ceramide synthesis and glycosylation, which was inferred from the occurrence of some unexpected sphingolipids produced by $S$. cerevisiae and P. pastoris transformed with GCS from different sources. In this study, GCS null mutants of $P$. pastoris and $C$. albicans were generated. Both mutants were still viable and grew like the parental strains on different culture media. GCSs from Homo sapiens, Gossypium arboreum, $P$. pastoris, C. albicans, and M. grisea were then expressed in the P. pastoris GCS null mutant strain, 
which resulted in the formation of structurally diverse GlcCer molecules. Yeast cells expressing the human GCS, for instance, produced five different GlcCer molecular species, with ceramide backbones corresponding to 18:0-18:0, 18:0(2-OH)-18:0, 18:0$18: 1^{\Delta 4}, 18: 0-18: 2^{\Delta 4,8}, 18: 0(2-\mathrm{OH})-18: 1^{\Delta 4}$, and 18:0(2-OH)-18:2 $2^{\Delta 4,8}$, which may all be regarded as biosynthetic precursors of 18:0(2-OH)-18:2 $2^{\Delta 4,8} 9 \mathrm{~m}$, which is the major ceramide moiety in CMHs from many fungal species. If this hypothesis is correct, it is possible to suggest a sequential modification of the sphingoid base starting with the introduction of the $\Delta 4$-double bond followed by the $\Delta 8$-unsaturation and a final methylation at $\mathrm{C} 9$. However, it is not possible to conclude whether these modifications occur at the free sphingobase, in its acylated form, or even after glycosylation of the ceramide.

Structural analysis revealed that, in the transformed cells described above, ceramide backbones containing phytosphingosine and a VLCFA molecule were also detected. This is a very significant finding, since such fungal ceramides were thought to be exclusively used for the synthesis of inositol-containing sphingolipids. This observation confirmed a single previous report, which has been further supported by our group, as described below.

\section{GLYCOSYLCERAMIDES WITH PHYTO-}

SPHINGOSINE- OR 4, 8-DIENE-9-METHYL-

SPHINGOBASE-CONTAINING CERAMIDES: THE

\section{M. grisea PARADIGM}

Recent studies from our group demonstrate that phytoceramide can be alternatively glycosylated to ceramide dihexosides in M. grisea (Maciel et al. 2002). These results reveal that phytoceramides in fungi can be modified to generate unconventional GSLs, which agrees with previous reports (Lester et al. 1974).

In summary, fungal cells are believed to have two different pools of ceramides to be used for the synthesis of different sphingolipids (Leipelt et al. 2001). Ceramide backbones with $\mathrm{C} 16$ or $\mathrm{C} 18$ fatty acids linked to a 4, 8-diene-9-methyl-sphingobase, which were widely identified in several fungal species (Table I), are thought to be exclusively used as precursors of glucosylceramide (GlcCer) synthesis. In contrast, ceramide backbones with relatively long chain C24 and C26 fatty acids bound to phytosphingosine were thought to be restricted to the synthesis of the inositol-containing phosphosphingolipids. In a recent investigation, however, Leipelt et al. (2001) have identified and characterized novel glucosylceramide synthases from plants, animals and fungi, including $M$. grisea. Genetic approaches revealed that the expression of the GCS from $M$. grisea in a $P$. pastoris GCS null mutant resulted in the biosynthesis of GlcCer with the usual ceramide moieties comprising $\mathrm{C} 16$ and $\mathrm{C} 18$ fatty acids in an amidic linkage with 9-methyl-4, 8 -sphingadienine, but also in that of GlcCer with phytosphingosine and mainly long-chain (C26) $\alpha$ hydroxy fatty acids in amide linkage. These results indicated that GCS could accept both classes of ceramide as substrates to form GlcCer.

We have demonstrated by structural determinations that the $M$. grisea enzymatic apparatus is able to add glucose units to both phytosphingosineand 9-methyl-sphingadienine-containing ceramides and form GlcCer under normal growth conditions, which is in accordance with the results of Leipelt et al. (2001) regarding GCS specificity. In $M$. grisea, therefore, long chain ceramides should also serve as substrates for the action of GCS, which would be followed by the action of galactosyl transferases to finally form $\mathrm{CDH}$. These possibilities are supported by the results of Lester and co-workers (Lester et al. 1974), who described the occurrence of a ceramide tetrahexoside consisting of $\left(\mathrm{Gal}_{3} \mathrm{Glc}\right)$ $N$-hydroxytetracosonyl-hydroxysphinganine in $N$. crassa. Taken together, these observations raise the assumption that, contrarily to what has been proposed for several species of fungi, separation of ceramide pools for glycosphingolipid biosynthesis may not occur in fungi such as $M$. grisea. These results and previous ones, therefore, suggest the occurrence of an alternative path of ceramide glycosylation in fungal cells (Figure 3). 


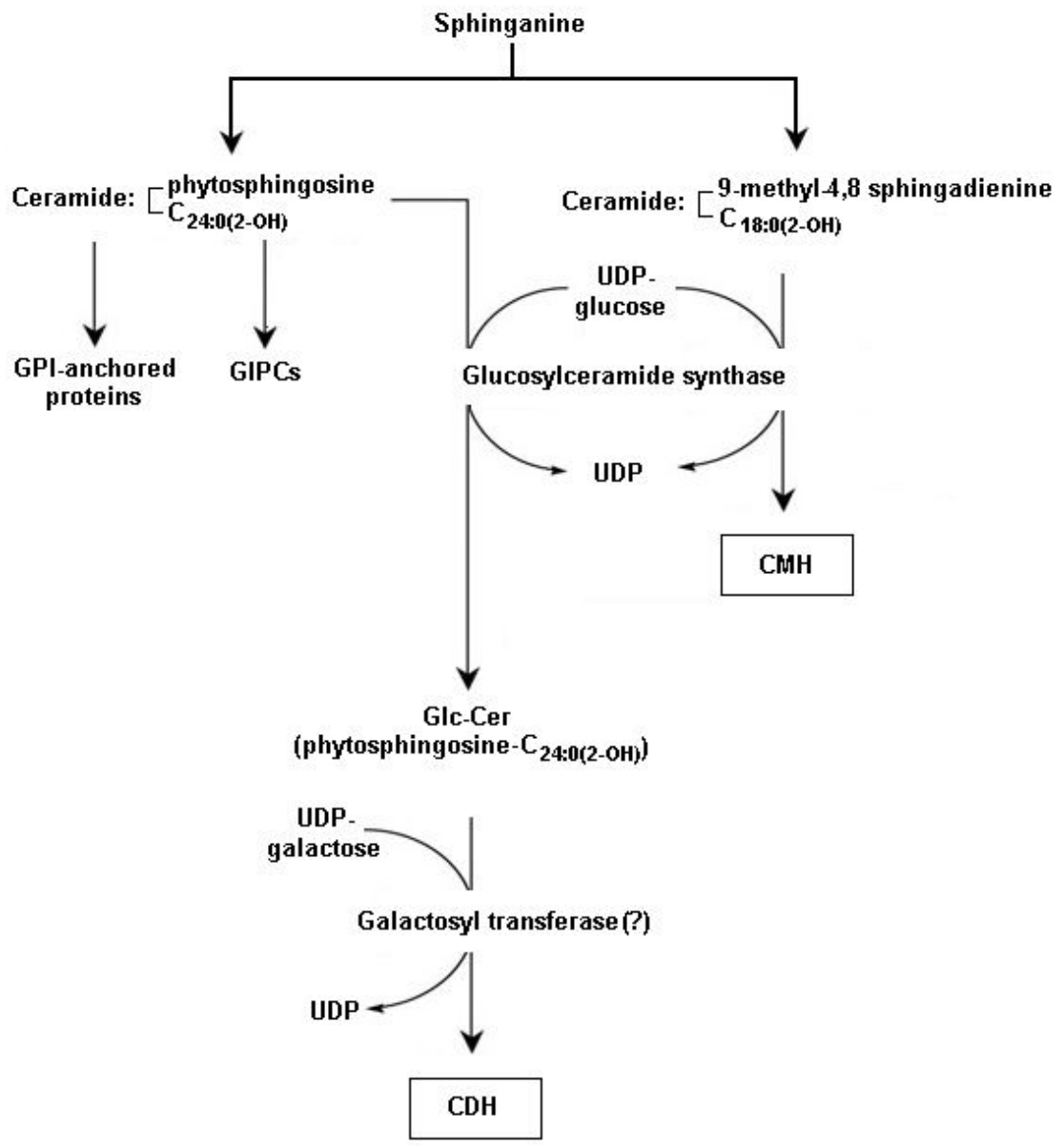

Fig. 3 - Glycosylation of ceramide-containing fungal lipids, modified from Maciel et al. (2002) and Leipelt et al. (2001). Steps of hydroxylation, desaturation or methylation (not shown in Figure) should follow biosynthesis of ceramide backbones for further addition of sugar units. In M. grisea, we propose that the two classes of ceramides would be used by GCS, under standard cellular conditions, as substrates to form GlcCer. Phytosphingosinecontaining GlcCer would be sequentially glycosylated with the addition of a galactose residue, catalyzed by a still uncharacterized galactosyl transferase.

\section{BIOLOGICAL FUNCTIONS} OF FUNGAL CEREBROSIDES

Although largely distributed in fungi and, in addition, displaying highly conserved structures, the understanding of the functions of $\mathrm{CMHs}$ in fungal cells is only beginning to be understood. The old concept that cerebrosides and other glycosphingolipids are membrane structural components with exclusive role of filling gaps (Koscielak 1986) is obviously simplistic, since it is now clear that such molecules are involved in cell growth, differentiation and signaling (Hakomori 1990). In fungal cells, CMHs have been characterized as bioactive molecules with several distinct roles. For instance, the phytopathogen $M$. grisea produces active elicitors of the hypersensitive response in rice (Umemura et al. 2000, Koga et al. 1998) that were identified as monohexosylceramides. Treatment of rice leaves with $M$. grisea CMHs induced the accumulation of 
antimicrobial compounds, plant cell death, expression of pathogenesis-related proteins in rice leaves, and effectively protected rice plants against fungal infection.

Fungal cerebrosides were also characterized as antigenic molecules directly or indirectly involved in cell growth or differentiation in S. commune (Kawai and Ikeda 1982), C. neoformans (Rodrigues et al. 2000), P. boydii (Pinto et al. 2002), C. albicans (Pinto et al. 2002), A. nidulans (Levery et al. 2002) and A. fumigatus (Levery et al. 2002). Most of these reports, which are discussed below, are very recent in the current literature and represent an open and new field in the biology of fungal glycosphingolipids. We will summarize these studies, mainly focusing on the cellular distribution of fungal $\mathrm{CMHs}$ and their association with growth or differentiation.

\section{Are CMHs Involved in Fungal Growth?}

GSLs were shown to be antigenic in different infectious agents. For instance, GSLs from Trypanosoma cruzi epimastigotes react with sera from patients with Chagas' disease and this reactivity is modulated by the ceramide structure (Villas-Boas et al. 1994b). Schistosome glycolipids are recognized by IgE, which may have a role in immunity against Schistosoma mansoni (Van Der Kleij et al. 1999). In $P$. brasiliensis, a galactofuranose-containing GSL was reactive with antibodies from patients with paracoccidioidomycosis (Toledo et al. 1995). Such reactivity was attributed to the nonreducing galactofuranosyl residue in the carbohydrate chain.

As extensively described before, fungal cerebrosides are very similar in that they all contain a 9-methyl-4, 8-sphingadienine in combination with $\mathrm{N}-2$ '-hydroxy fatty acids that are saturated or unsaturated. Hydroxylation at position 2 of the fatty acid is apparently important for antigenicity of the $\mathrm{CMH}$, and possible epitopes involve both glucose and the hydroxylated fatty acid, with modulation by the sphingosine-derived base. Conformer 4 of glucosylceramide as studied by Nyholm and Pascher (1993a, b), which is allowed in a membrane layer, further stabilized by a hydrogen bond between the
2-OH group on the fatty acid and the 6-OH group on the glucose residue, in addition to the hydrogen bond between glucose $\mathrm{O} 5$ and the amide hydrogen, is a candidate for carrying epitopes reactive with antibodies to $\mathrm{CMH}$.

In the human pathogen $C$. neoformans, a major $\mathrm{CMH}$ was characterized by our group as a $\beta$ glucosylceramide, containing the conserved base 9methyl-4, 8-sphingadienine in amidic linkage to 2hydroxyoctadecanoic acid (Rodrigues et al. 2000). This molecule was recognized by sera from patients with cryptococcosis and a few other mycoses, indicating that CMHs are immunogenic glycolipids that induce the production of human antibodies during fungal infections. Aiming at the determination of the cellular distribution of CMHs in C. neoformans, we purified the specific antibodies from patients' sera, by immunoadsorption on the purified glycolipid followed by protein $\mathrm{G}$ affinity chromatography, to be used in immunofluorescence experiments. Interestingly, antibodies to $\mathrm{CMH}$ reacted with the cryptococcal surface mostly at the sites of cell division.

Immunofluorescence analysis with antibodies to CMH confirmed that the cryptococcal glucosylceramide in fact accumulated mostly at the budding sites of dividing cells (Rodrigues et al. 2000) with a more disperse distribution at the cell surface of nondividing cells (Figure 4). In these experiments, the increased density of sphingolipid molecules seemed to correlate with thickening of the cell wall, hence with its biosynthesis. These results raised the possibility that fungal CMHs were involved in fungal growth, which was supported by further experiments using human antibodies to glucosylceramide. The addition of these antibodies to the culture medium of C. neoformans yeasts generated an extensive inhibition of fungal budding and, consequently, growth (Rodrigues et al. 2000).

An association between the expression of CMHs in fungi and growth or differentiation is supported by other reports. For instance, Kawai and Ikeda (Kawai and Ikeda 1982) showed that fungal glucocerebrosides had fruiting-inducing activity in bioassays with $S$. commune. The intact 9-methyl- 

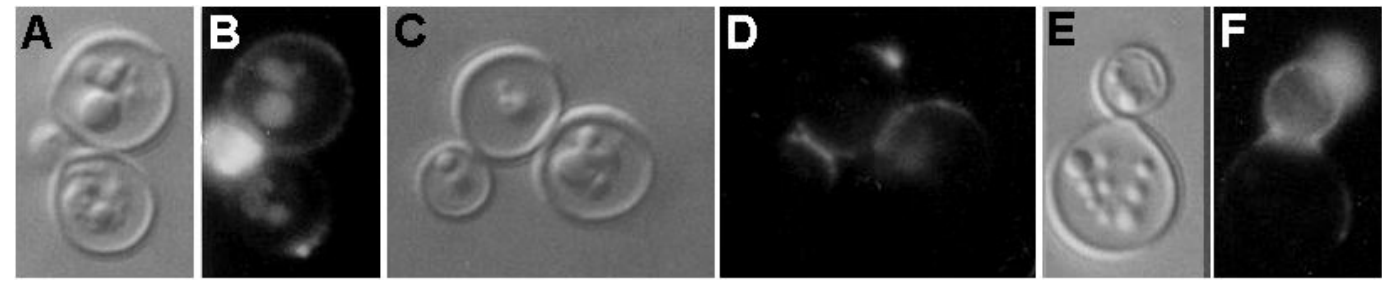

Fig. 4 - Immunofluorescence analysis showing that antibodies to $\mathrm{CMH}$ preferentially recognize the sites of cell division in $C$. neoformans. Panels A, C and E show cryptococcal yeasts under differential interferential contrast, while panels B, D and F show the reactivity of fungal cells with anti-glucosylceramide antibodies. For experimental details, see Rodrigues et al. (2000).

4, 8-sphingadienine but not the $\beta$-glucopyranosyl residue was essential for this activity. Accordingly, the following observations indicated that an antiglucosylceramide monoclonal antibody reacted preferably with the conidiophore of A. fumigatus (Toledo et al. 2001b). In this context, we investigated whether CMHs and related antibodies interfered with cell growth or differentiation in other fungal species.

As mentioned above, a serological cross-reactivity between cryptococcal CMHs and sera from patients with cryptococcosis, histoplasmosis, aspergillosis and paracoccidioidomycosis was observed (Rodrigues et al. 2000). The recognition of a glucosylceramide from $C$. neoformans by sera from individuals with different mycoses was suggestive that, during fungal infections, human antibodies are produced against similar antigens from distinct species. In this context, antibodies to $\mathrm{CMH}$ could interfere with cell division processes in different $\mathrm{CMH}-$ containing fungal cells.

Conserved CMHs from $P$. boydii are antigens recognized by antibodies from a rabbit infected with this fungus (Pinto et al. 2002). These antibodies were purified as described before and used in immunofluorescence analysis. Interestingly, reactions of these antibodies and $P$. boydii conidial forms were absent or very weak, while mycelia and pseudohyphae were strongly reactive (Pinto et al. 2002). These results suggest that CMHs are differentially expressed in $P$. boydii according with the morpho- logical phase. Biosynthesis, expression or chemical structures of CMHs seem to be modified during the conidia $\rightarrow$ mycelium transition, which suggests a role for $\mathrm{CMHs}$ in fungal differentiation. In accordance with this is the observation that antibodies to $\mathrm{CMH}$ were able to inhibit the formation of germ tube-like structures in $P$. boydii, although they did not influence mycelial growth (Pinto et al. 2002) (Figure 5). We have shown (unpublished data) that germ tubes are induced after the contact of $P$. boydii conidia with animal cells, a step preceding efficient fungal invasion. Germ tube formation is also recognized as a crucial event in tissue invasion by C. albicans (Gow 1997), a fungus that synthesizes CMHs (Matsubara et al. 1987) structurally similar to those previously described in other fungi and to that characterized from $P$. boydii. In this context, the influence of antibodies to $\mathrm{CMH}$ on $C$. albicans differentiation was also evaluated. As with $P$. boydii, anti-CMH antibodies inhibited germ tube formation in C. albicans (Pinto et al. 2002). Our most recent results demonstrate that polyclonal and monoclonal antibodies to $\mathrm{CMH}$ strongly inhibit the differentiation of the plant pathogen Colletotrichum gloeosporioides (Da Silva et al. unpublished results).

The involvement of CMHs in fungal development was further confirmed by experiments using a family of compounds known to inhibit glucosylceramide synthase in mammals. Two analogs, Dthreo-1-phenyl-2- palmitoyl-3- pyrrolidinopropanol (P4) and D-threo-3P, 4P-ethylenedioxy-P4, strongly 

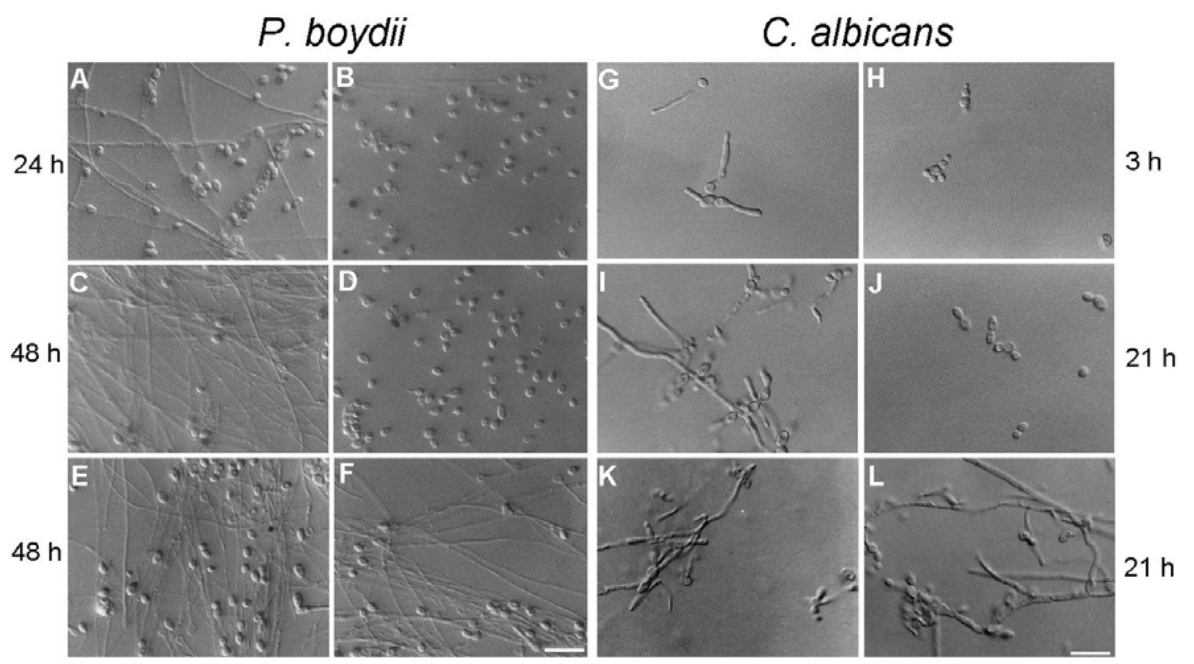

Fig. 5 - Antibodies to $\mathrm{CMH}$ inhibit germ tube formation in P. boydii and C. albicans. Panels show germ tube formation observed after 24 (A) and 48 (C and E) h of incubation of $P$. boydii in the RPMI medium, and after $3 \mathrm{~h}(\mathrm{G})$ and $21 \mathrm{~h}(\mathrm{I}$ and $\mathrm{K}$ ) of incubation of C. albicans in the same medium. Addition of antibodies to $\mathrm{CMH}$ inhibits differentiation of $P$. boydii (B and D) and C. albicans ( $\mathrm{H}$ and $\mathrm{J})$. In contrast, addition of control antibodies to the differentiation systems of $P$. boydii (F) and $C$. albicans (L) did not affect mycelium or germ tube formation. Bars represent $10 \mu \mathrm{m}$. Reproduced from Pinto et al. (2002), with permission from Oxford University Press.

inhibited germination and hyphal growth of $A$. nidulans and A. fumigatus (Levery et al. 2002). However, the mechanisms by which fungal $\mathrm{CMHs}$ act on cell growth or differentiation of fungi are not known, and there is controversial evidence in this field of research. For instance, $P$. pastoris glucosylceramide synthase null mutants are viable and grow like their parental cells in vitro (Leipelt et al. 2001). In addition, $C$. albicans null mutants were able to grow in both yeast and filamentous forms, indicating that $\mathrm{CMHs}$ do not play essential roles during growth and differentiation of these organisms (Leipelt et al. 2001). These observations could be initially explained by the occurrence of speciesspecific functions of CMHs and related enzymes in fungal cells. However, the cellular distribution of $\mathrm{CMHs}$ in fungi suggests the participation of complementary surface structures possibly involved in the antifungal mechanisms generated after blocking CMHs with antibodies, as discussed later.

The mechanisms by which anti-CMH antibod- ies inhibit fungal growth and/or differentiation remain to be established, but there is a possibility that $\mathrm{CMHs}$ are associated with enzymes involved in the hydrolysis and synthesis of the cell wall and/or with GPI-anchored precursors during cell differentiation and division. In this context, binding of antibodies to CMHs could impair the action of $\mathrm{CMH}$-associated functional proteins inhibiting cell wall synthesis.

\section{Surface Distribution of Fungal CMHs}

In many cell types, cerebrosides were thought to be exclusive membrane components, due to their hydrophobic properties. However, the presence of CMHs as structural components of the cell wall of C. neoformans was clearly demonstrated by electron microscopy of yeast cells labeled with immunogoldantibodies (Rodrigues et al. 2000). An abundant deposition of gold particles was observed on the cryptococcal wall rather than on the plasma membrane, (Figure 6), indicating that the antibody-reactive epitopes of CMH may be sterically accessible only after 


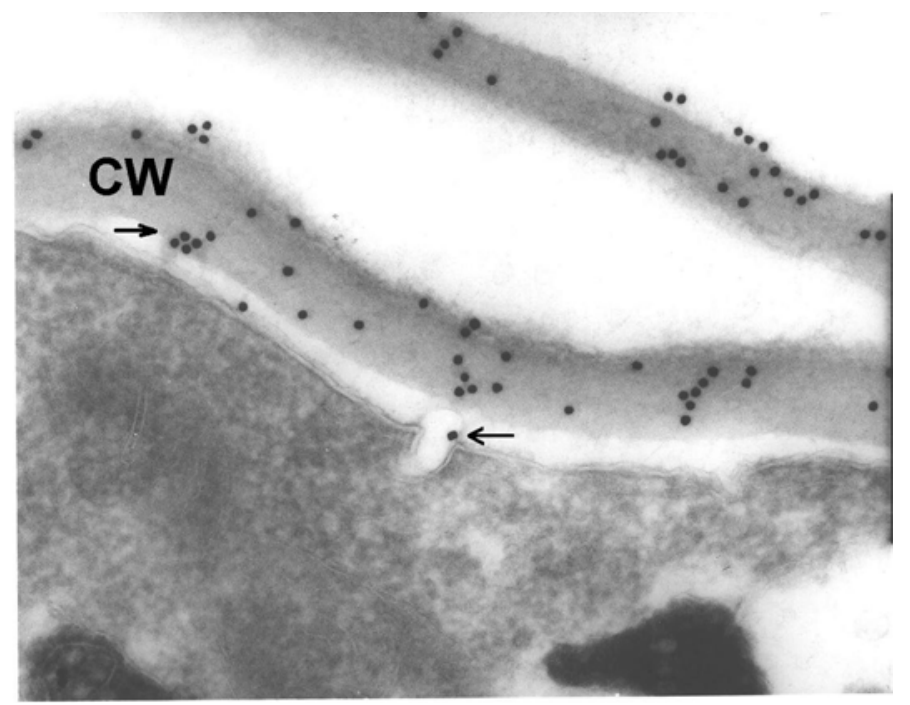

Fig. 6-Transmission electron microscopy showing an extensive binding of antibodies to $\mathrm{CMH}$ to the cell wall $(\mathrm{CW})$ of $C$. neoformans. Possible $\mathrm{CMH}$-containing vesicles are seen (arrows) in $C$. neoformans cells. These vesicles, which are recognized by antibodies to $\mathrm{CMH}$, can move across the periplasmic space and deposit cell membrane constituents on the cell wall. For experimental details, see Rodrigues et al. (2000).

transfer of the glycosphingolipids to the cell wall. Sites of transport of the presumed CMH-containing vesicles from the plasma membrane to the cell wall, were also suggested (Rodrigues et al. 2000) (Figure 6). The association of CMHs with the cryptococcal cell wall was confirmed by immunochemical analysis, which showed that, by thin layer chromatography, orcinol-reactive bands with $\mathrm{R}_{\mathrm{F}}$ similar to that of purified CMHs were detected in extracts from isolated cell wall preparations (Rodrigues et al. 2000). These bands were recognized by antibodies to $\mathrm{CMH}$, suggesting that cerebrosides actually make part of the fungal cell wall components.

What would be the explanation for the presence of CMHs at the fungal wall? Glycosphingolipids form, with sterols and GPI-anchored proteins, detergent-insoluble lipid rafts on the plasma membrane (Muniz and Riezman 2000, Schroeder et al. 1998, Zhang and Thompson 1997). They are required for the processing of GPI-anchored proteins in yeasts, making part of vesicles that link the RES to Golgi to the plasma membrane (Hor- vath et al. 1994, Skrzypek et al. 1997, Sutterlin et al. 1997). For the synthesis of the cell wall structural network it has been proposed that GPIanchors have a pivotal constitutive role (De Sampaio et al. 1999). A truncated GPI anchor which no longer contains inositol and glucosamine is the substrate for a phosphate-linked $\beta$-1, 6-glucan extension (Shahinian and Bussey 2000, Van Der Vaart et al. 1996). GPI-anchors can be liberated in the periplasmic space by the action of phospholipase C (PI-PLC) as present in S. cerevisiae (Flick and Thorner 1993) and abundantly expressed in P. brasiliensis (Heise et al. 1995), or could be transported to the cell wall in vesicles. This may happen due to the inability of GPI-anchor cleavage by PI-PLC, a property of inositol-acylated molecules found in $C$. neoformans (Franzot and Doering 1999) or to a more generalized process in which precursor molecules and enzymes are transferred to the cell wall in vesicles originating from the plasma membrane. Assuming then that glycosphingolipids closely associated with GPI precursors as in lipid rafts and pre- 
sumably also biosynthetic enzymes are transported to the cell wall in vesicles, CMHs could accumulate on the fungal cell wall (Figure 6).

This hypothesis could provide an explanation for the antifungal action of antibodies to $\mathrm{CMH}$, since binding of antibodies to cell wall components could interfere with the biosynthesis and organization of the cell wall polymers. For instance, antibodies to melanin, which is deposited onto the cell wall of C. neoformans, strongly inhibit the growth of yeast cells (Rosas et al. 2001). Similarly, human antibodies to melanin inhibit the growth of F. pedrosoi, the ethiological agent of chromoblastomycosis (Alviano et al. 2004). In Fusarium sp (Ciopraga et al. 1999), treatment with wheat germ agglutinin (WGA), which has a known affinity for chitin, resulted in alterations in the germ tube formation and caused cell lysis. As a consequence, fungal infection did not spread with lectin-treated Fusarium. In summary, it seems clear that binding of several ligands to the cell surface could therefore impair the biological functions of molecules involved in wall assembly and inhibit fungal growth. The inhibitory activity of antibodies to $\mathrm{CMH}$, however, may involve additional mechanisms, since they could impair the utilization and reactivity of the carried components. Antibody inhibition of yeast budding can also be correlated with the increased secretion of enzymecontaining vesicles during bud formation (Moor and Mühlethaler 1963).

\section{PERSPECTIVES}

As pointed out by Warnecke and Heinz (2003), the exploration of glycosphingolipid functions in fungi is only in its infancy. To understand how cerebrosides influence the biology of fungal cells, a profound knowledge of structural and biosynthetic aspects of these molecules is still required. In addition, the generation of mutants lacking key enzymatic activities involved in cerebroside biosynthesis is of fundamental applicability for studies on fungal pathogenesis. The development of chemical or immunological agents with unquestionable selectivity to inhibit CMH synthesis and expression is also necessary to evaluate if cerebrosides are in fact good targets for the treatment of fungal infections.

\section{ACKNOWLEDGMENTS}

This work was supported by grants from Conselho Nacional de Desenvolvimento Científico e Tecnológico $(\mathrm{CNPq})$, Fundação de Amparo a Pesquisa no Estado do Rio de Janeiro Carlos Chagas Filho (FAPERJ), Fundação Universitária José Bonifácio (FUJB), and Coordenação de Aperfeiçoamento de Pessoal de Nível Superior (CAPES). We thank Kildare R. Miranda and Anderson J. Franzen for the micrograph used in Figure 6.

\section{RESUMO}

Monohexosilceramidas (CMHs, cerebrosídios) são glicoesfingolipídios compostos de uma ceramida hidrofóbica ligada a uma unidade de açúcar. Em células fúngicas, CMHs são moléculas muito bem conservadas, consistindo de uma porção ceramida contendo 9-metil-4,8-esfingadienina ligada através de uma ligação amida aos ácidos 2hidroxioctadecanoico ou 2-hidroxihexadecanoico e uma porção carboidrato constituída de uma unidade de glucose ou galactose. Ceramidas contendo 9-metil-4,8-esfingadienina são normalmente glicosiladas formando os cerebrosídios fúngicos; no entanto uma descrição recente de uma dihexosilceramida (CDH) em Magnaporthe grisea, apresentando fitoesfingosina sugere a existência de vias alternativas para a glicosilação de ceramidas nas células fúngicas. Além de suas particularidades estruturais, os CMHs de fungos apresentam uma distribuição celular incomum e funções biológicas características. Monohexosilceramidas estão aparententemente envolvidas nas transições morfológicas ou no crescimento dos fungos Pseudallescheria boydii, Candida albicans, Cryptococcus neoformans, Aspergillus nidulans, A. fumigatus e Schizophylum commune. A elucidação dos aspectos estruturais e funcionais dos cerebrosídios fúngicos pode contribuir para a descoberta de novos agentes antifúngicos que inibam o crescimento ou a diferenciação de espécies patogênicas.

Palavras-chave: glucosilceramidas, cerebrosídios, glicoesfingolipídios, fungos patogênicos, terapia antifúngica. 


\section{REFERENCES}

Alviano DS, Franzen AJ, Travassos LR, Holandino C, Rosental S, Ejzemberg R, Alviano CS and Rodrigues ML. 2004. Melanin from Fonsecaea pedrosoi Induces Production of Human Antifungal Antibodies and Enhances the Antimicrobial Efficacy of Phagocytes. Infection and Immunity, in press.

Ballio A, Casinovi CG, Framondino M, Marino G, Nota G and Santurbano B. 1979. A new cerebroside from Fusicoccum amydali Del. Biochim Biophys Acta 27: 51-60.

Chung N, Mao C, Heitman J, Hannun YA and Obeid LM. 2001. Phytosphingosine as a specific inhibitor of growth and nutrient import in Saccharomyces cerevisae. J Biol Chem 276: 35614-35621.

Ciopraga J, Gozia O, Tudor R, Brezuica L and Doyle RJ. 1999. Fusarium sp. growth inhibition by wheat germ agglutinin. Biochim Biophys Acta 428: 424-432.

De Sampaio G, Bourdineaud JP and Lauguin GJ. 1999. A constitutive role for GPI anchors in Saccharomyces cerevisiae: cell wall targeting. Mol Microbiol 34: 247-256.

Dickson RC And Lester RL. 2002. Sphingolipid functions in Saccharomyces cerevisae. Biochim Biophys Acta 1583: 13-25.

Dromer F AND DuPONT B. 1996. The increasing problem of fungal infections in the immunocompromised host. J Mycol Méd 6 (Suppl I): 1-6.

Duarte RS, Polycarpo CR, Wait R, Hartmann R AND BArreto-Bergter E. 1998. Structural characterization of neutral glycosphingolipids from Fusarium species. Biochim Biophys Acta 1390: 186-196.

Flick JS AND Thorner J. 1993. Genetic and biochemical characterization of a phosphatidylinositolspecific phospholipase $\mathrm{C}$ in Saccharomyces cerevisiae. Mol Cell Biol 13: 5861-5876.

Fodegal M, Mickos H ANd Norberg T. 1986. Isolation of N-2'-hydroxydecanoyl-1-O- $\beta$-D-glucopyranosil9-methyl-4,8-D-erythro-sphingadienine from fruiting bodies of two Basidiomycetes fungi. Glycoconjugate J 3: 233-237.

Folch J, Lees M and Sloane Stanley GH. 1957. A simple method for the isolation and purification of total lipids from animal tissues. J Biol Chem 226: 497-509.
Franzot SP AND Doering TL. 1999. Inositol acylation of glycosylphosphatidylinositols in the pathogenic fungus Cryptococcus neoformans and the model yeast Saccharomyces cerevisiae. Biochem J 340 (Pt 1): 25-32.

Fujino Y AND OHNishi M. 1977. Structure of cerebroside in Aspergillus oryzae. Biochim Biophys Acta 486: 161-171.

Gao JM, Hu L, Dong ZJ and Liu JK. 2001. New glycosphingolipid containing an unusual sphingoid base from the basidiomycete Polyporus ellisi. Lipids 36: 521-527.

Georgopapadakou NH. 2000. Antifungals targeted to sphingolipid synthesis: focus on inositol phosphorylceramide synthase. Expert Opin Investig Drugs 9: 1787-1796.

Gow NA. 1997. Germ tube growth of Candida albicans. Curr Top Med Mycol 8: 43-55.

HAKOMORi S. 1990. Bifunctional role of glycosphingolipids. Modulators for transmembrane signaling and mediators for cellular interactions. J Biol Chem 265: 18713-18716.

HAKOMORI S. 1993. Structure and function of sphingoglycolipids in transmembrane signalling and cell-cell interactions. Biochem Soc Trans 3: 583-595.

Heidler AS And Radding JA. 1995. The AUR 1 gene in Saccharomyces cerevisae encodes dominant resistence to the antifungal agent aureobasidin A (LY295337). Antimicrob Agents Chemother 39: 2765-2769.

Heise N, Travassos LR and Almeida ML. 1995. Pacoccidioides brasiliensis expresses both glycosylphosphatidylinositol-anchored proteins and a potent phospholipase C Exp Mycol 19: 111-119.

Horvath A, Sutterlin C, Manning-Krieg U, Movva NR and Riezman H. 1994. Ceramide synthesis enhances transport of GPI-anchored proteins to the Golgi apparatus in yeast. EMBO J 13: 3687-3695.

Jenkins GM, Richards A, Wahl T, Mao C, Obeid L AND HANNUN Y. 1997. Involvement of yeast sphingolipids in the heat stress response of Saccharomyces cerevisae. J Biol Chem 272: 32566-32572.

KarlsSON KA, LefFler H AND SAMuelsson BE. 1979. Characterization of cerebroside (monoglycosylceramide) from the sea anemone, Metridium senile: identification of the major long-chain base as an usual 
dienic base with a methyl branch at a double bond. Biochim Biophys Acta 574: 79-93.

Kasahara K and Sanai Y. 2000. Functional roles of glycosphingolipids in signal transduction via lipids rafts. Glycoconjugate J 17: 153-162.

KAWAI G. 1989. Molecular species of cerebrosides in fruiting bodies of Lentimus edodes and their biological activity. Biochim Biophys Acta 1001: 185-190.

KAWAI G AND IKEDA Y. 1982. Fruiting inducing activity of cerebrosides observed with Schizophyllum commune. Biochim Biophys Acta 719: 612-618.

Koga J, Yamauchi T, Shimura M, Ogawa N, Oshima K, Umemura K, Kiluchi M and Ogasawara N. 1998. Cerebrosides A and C, sphingolipid elicitors of hipersensitive cell death and phytoalexin accumulation in rice plants. J Biol Chem 273: 31985-31991.

Koscielak J. 1986. A hypothesis on the biological of $\mathrm{ABH}$, Lewis and $\mathrm{P}$ blood groups determinant structures in glycosphingolipids and glycoproteins. Glycoconjugate $\mathrm{J}$ 3: 95-108.

Leipelt M, Warnecke D, Zähringer U, OtT C, Müller F, Hube B and Heinz E. 2001. Glucosylceramide synthases, a gene family responsible for the biosynthesis of glucosphingolipids in animals, plants, and fungi. J Biol Chem 276: 33621-33629.

Lester RL, Smith SW, Wells GB, Rees DC and Angus WW. 1974. The isolation and partial characterization of two novel sphingolipids from Neurospora crassa: di(inositolphosphoryl)ceramide and [(gal $)_{3}$ glu] ceramide. J Biol Chem 249: 3388-3394.

Levery SB, Toledo MS, Straus AH and Takahashi HK. 1998. Structure elucidation of sphingolipids from the mycopathogen Paracoccidioides brasiliensis: an immunodominant beta-galactofuranose residue is carried by a novel glycosylinositol phosphorylceramide antigen. Biochemistry 37: 87648775 .

Levery SB, Toledo MS, Doong RL, Straus AH ANd TAKAHASHI HK. 2000. Comparative analysis of ceramide structural modification found in fungal cerebrosides by electrospray tandem mass spectrometry with low energy collision-induced dissociation of $\mathrm{Li}^{+}$ adduct ions. Rapid Commun Mass Spectrom 14: 551-563.

Levery SB, Momany M, Lindsey R, Toledo M, Shayman J, Fuller M, Brooks K, Doong RL, Straus AH AND TaKahashi HK. 2002. Disruption of the glucosylceramide biosynthetic pathway in Aspergillus nidulans and Aspergillus fumigatus by inhibitors of UDP-Glc:ceramide glucosyltransferase strongly affects spore germination, cell and hyphal growth. FEBS Lett 525: 59-64.

Luberto C, Toffaletti DL, Wills EA, Tucker SC, Casadevall A, Perfect JR, Hannun YA and Del Poeta MM. 2001. Roles for inositol-phosphoryl ceramide synthase 1 (IPC1) in pathogenesis of C. neoformans. Genes Dev 15: 201-212.

Maciel DM, Rodrigues ML, Wait R, Villas Boas MH, Tisher CA and Barreto-Bergter E. 2002. Glycosphingolipids from Magnaporthe grisea cells: expression of a ceramide dihexoside presenting phytosphingosine as the long chain base. Arch Biochem Biophys 405: 205-213.

Matsubara T, Hayashi A, Banno Y, Morita T And Nozawa Y. 1987. Cerebroside of the dimorphic human pathogen Candida albicans. Chem Phys Lipids 43: $1-12$.

Mineki S, Iida M and Tsutsumi T. 1994. A new cerebroside of the n-alkane-assimilating yeast Candida deformans. J Ferment Bioeng 78: 327-330.

Mizushina Y, Hanashima L, Yamaguchi T, Takemura M, Sugawara F, Saneyoshi M, Matsukage A, Yoshida S AND Sakaguchi K. 1998. A mushroom fruiting body-inducing substance inhibits activities of replicative DNA polymerases. Biochem Biophys Res Commun 249: 17-22.

Moor H and MüHlethaler. 1963. Fine structure in frozen-etched yeast cells. J Cell Biol 17: 609-628.

Muniz M ANd Riezman H. 2000. Intracellular transport of GPI-anchored proteins. EMBO J 148: 925-930.

NG KH ANd LANEELE MA. 1977. Lipids of the yeast Hansenula anomala. Biochimie 59: 97-104.

Nyholm PG AND PAScher I. 1993a. Orientation of the saccharide chains of glycolipids at the membrane surface: conformational analysis of the glucose-ceramide and the glucose-glyceride linkages using molecular mechanics (MM3). Biochemistry 32: $1225-1234$.

Nyholm PG ANd Pascher I. 1993b. Steric presentation and recognition of the saccharide chains of glycolipids at the cell surface: favoured conformations of the saccharide-lipid linkage calculated using molecular mechanics (MM3). Int J Biol Macromol 15: 43-51. 
Obeid LM, Окамото Y and Mao C. 2002. Yeast sphingolipids: metabolism and biology. Biochim Biophys Acta 30: 163-171.

Pinto MR, Rodrigues ML, Travassos LR, Haido RMT, Wait R and Barreto-Bergter E. 2002. Characterization of glucosylceramides in Pseudallescheria boydii and their involvement in fungal differentiation. Glycobiology 12: 251-260.

Qi J, OJiKa M and SaKagami Y. 2001. Neuritogenic cerebrosides from an edible Chinese mushroom. 2. Structures of two additional termitomycesphins and activity enhancement of an inactive cerebroside by hydroxylation. Bioorg Med Chem 9: 2171-2177.

Rodrigues ML, Travassos LR, Miranda KR, Frazen AS, Rozental S, De Souza W, Alviano CS ANd Barreto-Bergter E. 2000. Human antibodies against a purified glucosylceramide from Cryptococcus neoformans inhibit cell budding and growth. Infect Immun 68: 7049-7060.

Rosas AL, Nosanchuk JD and Casadevall A. 2001. Passive immunization with melanin-binding monoclonal antibodies prolongs survival of mice with lethal Cryptococcus neoformans infection. Infect Immun 69: 3410-3412.

SAKAKI T, ZÄHRINGER U, WARNECKE DC, FAHL A, Knogge W and Heinz E. 2001. Sterol glycosides and cerebrosides accumulate in Pichia pastoris, Rhynchosporium secalis and others fungi under normal conditions or under heat shock and ethanol stress. Yeast 18: 679-695.

Sawabe A, Morita M, OKamoto T and Ouchi S. 1994. The location of double bonds in a cerebroside from edible fungi (mushroom) estimated by B/E linked scan fast atom bombardment mass spectrometry. Biol Mass Spectrom 23: 660-664.

SaWARdeker JS, Slonker JH ANd Jeanes A. 1965. Quantitative determination of monosaccharides as their alditol acetates by gas chromatography. Anal Chem 37: 1602-1604.

Schroeder RJ, Ahmed SN, Zhu Y, London E AND Brown DA. 1998. Cholesterol and sphingolipid enhance the Triton X-100 insolubility of glycosylphosphatidylinositol-anchored proteins by promoting the formation of detergent-insoluble ordered membrane domains. J Biol Chem 273: 1150-1157.

Shahinian S and Bussey H. 2000. Beta-1,6-Glucan synthesis in Saccharomyces cerevisiae. Mol Microbiol 35: 477-489.

SKRZyPek M, LeSter RL And Dickson RC. 1997. Suppressor gene analysis reveals an essential role for sphingolipids in transport of glycosylphosphatidylinositol-anchored proteins in Saccharomyces cerevisae. J Bacteriol 179: 1513-1520.

Sutterlin C, Doering TL, Schimmoller F, Schroder S AND RiEzMAN H. 1997. Specific requirements for the ER to Golgi transport of GPI-anchored proteins in yeast. J Cell Sci 110 (Part 21): 2703-2714.

Takahashi HK, Levery SB, Toledo MS, Suzuki E, Salyan ME, Hakomori S and Straus AH. 1996. Isolation and possible composition of glucosylceramides from Paracoccidioides brasiliensis. Braz $\mathrm{J}$ Med Biol Res 9: 1441-1444.

TAKakuwa N, Kinoshita M, Oda Y and OHnishi M. 2002. Existence of cerebroside in Saccharomyces kluyveri and its related species. FEMS Yeast Res 1496: 1-6.

Toledo MS, Suzuki E, Straus AH and Takahashi HK. 1995. Glycolipids from Paracoccidioides brasiliensis. Isolation of galactofuranose-containing glycolipid reactive with sera of patients with paracoccidioidomycosis. J Med Vet Mycol 33: 247-251.

Toledo MS, Levery SB, Straus AH, Suzuki E, Momany M, GlushKa J, Moulton JM and TaKaHASHI HK. 1999. Characterization of sphingolipids from mycopathogens: factors correlating with expression of 2-hydroxy fatty acyl (E)- $\Delta^{3}$-unsaturation in cerebrosides of Paracoccidioides brasiliensis and Aspergillus fumigatus. Biochemistry 38: 7294-7306.

Toledo MS, Levery SB, Straus AH and Takahashi HK. 2000. Dimorphic expression of cerebrosides in the mycopathogen Sporothrix schenckii. J Lip Res 41: 797-806.

Toledo MS, Levery SB, Suzuki E, Strauss AH and TAKAHASHI HK. 2001a. Characterization of cerebrosides from the thermally dimorphic mycopathogen Histoplasma capsulatum: expression of 2-hydroxy fatty $\mathrm{N}$-acyl (E)- $\Delta^{3}$-unsaturation correlates with the yeast-mycelium phase transition. Glycobiology 11: 113-124.

Toledo MS, Suzuky E, Levery SB, Straus AH AND TAKAHASHI HK. 2001b. Characterization of monoclonal antibody MEST-2 specific to gluco- 
sylceramide of fungi and plants. Glycobiology 11: 105-112.

Umemura K, Ogawa N, Yamauchi T, Iwata M, Shimura M AND Koga J. 2000. Cerebroside elicitors found in diverse phytopathogens activate defense responses in rice plants. Plant Cell Physiol 41: 676-683.

Van der Kleij D, Tielens AG and Yazdanbakhsh M. 1999. Recognition of schistosome glycolipids by immunoglobulin E: possible role in immunity. Infect Immun 67: 5946-5950.

VAn der VaARt JM, TE Biesebeke R, Chapman JW, KLIS FM AND Verrips CT. 1996. The beta-1,6glucan containing side-chain of cell wall proteins of Saccharomyces cerevisiae is bound to the glycan core of the GPI moiety. FEMS Microbiol Lett 145: 401-407.

Villas-Boas MHS, Egge H, Pohlentz G, HartMANN R AND BARreto-Bergter E. 1994a. Structural determination of N-2'-hydroxyoctadecenoyl-1O- beta-D- glucopyranosil-9-methyl-4,8- sphingadienine from species of Aspergillus. Chem Phys Lipids 70: 11-19.
Villas-Boas MHS, Da Silva MC, De Oliveira TG, Travassos LR and Barreto-Bergter E. 1994b. Reactivity of chagasic sera with crude and highly purified glycosphingolipid fractions from Trypanosoma cruzi epimastigotes. J Clin Lab Anal 8: 260-266.

WAGNER H AND ZoFCSIK W. 1966a. Sphingolipide und Glykolipide von Pilzen und höheren Pflanzen. Biochem Z 346: 333-342.

WAGNer H AND ZoFCSIK W. 1966b. Über neue Sphingolipide der Hefe. Biochem Z 344: 314-316.

WARnECKe D ANd HeInz E. 2003. Recently discovered functions of glucosylceramides in plants and fungi. Cell Mol Life Sci 60: 919-941.

Weiss B AND StILler RL. 1972. Sphingolipids of mushrooms. Biochemistry 11: 4552-4557.

Zhang X AND Thompson GA JR. 1997. An apparent association between glycosylphosphatidylinositolanchored proteins and a sphingolipid in Tetrahymena mimbres. Biochem J 323 (Pt 1): 197-206. 